STUDI

FRANCESI

\section{Studi Francesi}

Rivista quadrimestrale fondata da Franco Simone

143 (XLVIII | II) | 2004

Varia - fasc. II - maggio-agosto 2004

\title{
MARIE-JOSÉ BARBOT, Médiatisation dans \\ l'enseignement supérieur: vers un nouveau paradigme éducatif?
}

\section{Micaela Rossi}

\section{(2) OpenEdition}

1 Journals

\section{Édition électronique}

URL : https://journals.openedition.org/studifrancesi/43218

DOI : 10.4000/studifrancesi.43218

ISSN : 2427-5856

Éditeur

Rosenberg \& Sellier

\section{Édition imprimée}

Date de publication : 1 décembre 2004

Pagination : 434

ISSN : 0039-2944

\section{Référence électronique}

Micaela Rossi, « MARIE-JosÉ BARBOt, Médiatisation dans l'enseignement supérieur: vers un nouveau paradigme éducatif? », Studi Francesi [En ligne], 143 (XLVIII | II) | 2004, mis en ligne le 30 novembre 2015, consulté le 19 mai 2021. URL : http://journals.openedition.org/studifrancesi/43218 ; DOI : https://doi.org/10.4000/studifrancesi.43218

Ce document a été généré automatiquement le 19 mai 2021.

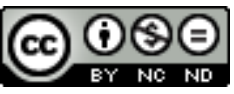

Studi Francesi è distribuita con Licenza Creative Commons Attribuzione - Non commerciale - Non opere derivate 4.0 Internazionale. 


\title{
MARIE-JOSÉ BARBOT, Médiatisation dans l'enseignement supérieur: vers un nouveau paradigme éducatif?
}

\author{
Micaela Rossi
}

\section{RÉFÉRENCE}

MARIE-JOSÉ BARBOT, Médiatisation dans l'enseignement supérieur: vers un nouveau paradigme éducatif? «Alsic», Vol. 6, Numéro 1, juin 2003, pp 169 - 182.

1 Sur la base d'une recherche-action réalisée sur sur l'Université en ligne (Uel), qui regroupe de nombreuses universités françaises offrant la possibilité d'accéder à des ressources d'autoformation en ligne (niveau DEUG I de sciences), cette étude se propose d'analyser l'impact des TICE dans la pratique universitaire, et de découvrir les motivations qui sont à l'origine de l'introduction des nouvelles technologies dans la didactique universitaire.

2 Selon l'auteur, «si on n'assure pas une modification du système éducatif, par un passage de l'enseignement transmissif à des apprentissages interactifs (...) les spécificités des technologies vont être phagocytées ou bien sous exploitées.» Les technologies fonctionnent en effet comme un amplificateur des pratiques existantes, et en tant que telles elles peuvent donc produire de nouveaux paradigmes éducatifs, fondés sur l'autonomie des apprenants et valorisant l'autoformation au sens le plus large (didactique, social, existentiel), mais elle peuvent aussi simplement renforcer et soutenir une pédagogie traditionnelle. Bien souvent, en effet, l'introduction des TICE dans les universités semble dictée par des préoccupations administratives et économiques plus que pédagogiques, et rares sont les cas où elle est accompagnée d'une réflexion méthodologique approfondie: en dépit de son statut de service public, l'Université se borne peut-être trop souvent à adopter ces nouvelles ressources sous la pression d'une logique économique. La recherche réalisée par l'auteur révèle que les pratiques en 
réalité diffèrent considérablement: alors que pour certains organismes la mise en place des TIC constitue une sorte de cheval de Troie, utile pour faire éclater les paradigmes de formation traditionnels et pour déclencher une nouvelle pratique pédagogique, pour d'autres elle ne représente qu'un outil de plus, voire un effet de mode auquel il faut s'adapter.

3 Finalement, le risque est celui d'introduire de façon massive les nouveaux médias sousestimant la portée du changement en acte, sans élaborer des interventions pédagogiques cohérentes qui tiennent en juste compte le moyen utilisé sans oublier les finalités des dispositifs d'enseignement-apprentissage. L'avenir de l'Université dépend, selon l'auteur, de la capacité de ses acteurs et décideurs d'éviter ce risque. 